\title{
Veterinary Responsibilities within the One Health Framework
}

\author{
J. van Herten ${ }^{1,2}$ (D) F. L. B. Meijboom ${ }^{3}$
}

Accepted: 22 February 2019 / Published online: 28 March 2019

(C) The Author(s) 2019

\begin{abstract}
Veterinarians play an essential role in the animal-based food chain. They are professionally responsible for the health of farm animals to secure food safety and public health. In the last decades, food scandals and zoonotic disease outbreaks have shown how much animal and human health are entangled. Therefore, the concept of One Health is broadly promoted within veterinary medicine. The profession embraces this idea that the health of humans, animals and the environment is inextricably linked and supports the related call for transdisciplinary collaboration. Especially in zoonotic disease control, the benefits of the cooperation between veterinarians and human doctors seem evident. However, applying a One Health approach also makes moral problems explicit. For instance, how should veterinarians deal with situations in which measures to protect public health negatively affect animal health? This creates a conflict of professional responsibilities. To deal with such moral problems and to strengthen the veterinarian's position, the starting point is a holistic perspective on One Health. We will argue for an 'encapsulated health' argument: the best way to safeguard human health is to promote the health of animals and the environment. This also holds for the responsibility of the veterinary profession: to serve public health, the central responsibility of veterinarians should be to be experts in animal health and welfare. We elaborate this point by using a case study on the role of the veterinary profession in antimicrobial resistance policies in the Netherlands.
\end{abstract}

Keywords Veterinarian · Responsibilities · One Health · Antimicrobial resistance

J. van Herten

joost.vanherten@wur.nl

1 Wageningen University and Research, Hollandseweg 1, NL- 6706 KNWageningen, The Netherlands

2 Royal Veterinary Association of the Netherlands, De Molen 77, 3995 AWHouten, The Netherlands

3 Faculty of Veterinary Medicine, Utrecht University, Yalelaan 2, NL-3584 CJUtrecht, The Netherlands 


\section{Introduction}

The motto of the Royal Veterinary Association of the Netherlands (RVAN) is: 'hominem animalumque saluti', which stands for: 'to the health of humans and animals'. This motto reflects the veterinary profession's responsibility for the health of both humans and animals. In this case, the order of words might suggest that human health is the primary concern of veterinarians. However, in our opinion, the health of humans and animals should not be addressed separately and the One Health paradigm seems to confirm this. In this paper we assess the impact of the One Health concept on the professional responsibilities of veterinarians.

One Health can be defined as the collaborative effort of multiple disciplines - working locally, nationally, and globally - to attain optimal health for people, animals and our environment (American Veterinary Medical Association 2008). In this view, especially veterinary and human medicine should cooperate to address health challenges at the human-animalenvironmental interface. One Health's starting point is the awareness that the health of humans, animals and the environment are intertwined. Up till now, ideas about One Health have been developed in the context of zoonotic diseases and beyond (Lerner and Berg 2015; Meijboom and Nieuwland 2018). Comparative or translational medicine and the positive effects of interaction with animals on the health of humans in hospitals, prisons or elderly homes, can all be covered under the One Health umbrella. Recently, this has even led to a proposal to stretch the concept towards 'One Welfare' (García Pinillos et al. 2016).

In this article, we focus on the added value of the One Health paradigm in the debate on veterinary responsibilities in the context of public health threats from livestock farming. We argue that (a) a One Health approach has direct consequences for veterinary responsibilities and (b) a holistic approach on One Health is necessary to deal with moral problems that arise from this. First, with regard to the point of professional responsibility, we claim that the veterinarian still remains primarily responsible for the health and welfare of animals. However, a One Health approach urges the veterinarian to look beyond the level of the individual animal and of disease symptoms. This entails, for instance, that the veterinarian's responsibility should include publicly addressing the underlying causes of the negative externalities of livestock farming. Due to the strong interconnectedness of human, animal and ecosystem health, keeping our animals healthy and caring for their welfare will automatically contribute to the reduction of health risks for all involved. This link is especially clear in the context of zoonotic diseases: healthy animals will reduce the risks of zoonotic disease transfer and thereby indirectly promote human health. This is the 'encapsulated health' argument.

Second, already in the current context veterinarians are confronted with moral problems in zoonotic disease control. For instance, when values of animal health and human health are in conflict (cf. Wright et al. 2010). One Health make these problems more complex, because this approach stresses that both animal and human health should be addressed in an integrated way. However, the One Health concept does not automatically provide moral guidance in these situations of conflict. One Health suggests that we should address health issues that affect humans, animals and the environment in a coherent way, but not how and why (Meijboom and Nieuwland 2018). The concerns about the lack of a normative framework for One Health have been addressed elsewhere in literature (Stephen and Karesh 2014; Degeling et al. 2016; van Herten et al. 2019). Important topics in this debate are the understanding of the concept of health and the view on the moral status of humans versus animals and the environment. A central question is whether or not health can be considered a universal good, shared by 
humans, animals and the environment (Degeling et al. 2016). If not, then perhaps One Health means nothing more than promoting public health. We argue that a holistic perspective on the One Health concept can be of relevance in the debate about veterinary responsibilities (van Herten and Meijboom 2018). Although One Health is not an ethical framework, the concept does help to search for innovations to deal with value conflicts that veterinarians encounter, such as the switch to a more preventive approach towards animal and human health.

To elaborate on the 'encapsulated health' argument and the proposal for an holistic perspective on the One Health concept we will use a case study focussing on the role of the veterinary profession in antimicrobial resistance policies in the Netherlands.

\section{Veterinary Responsibilities}

Societal expectations with regard to the professional responsibilities of veterinarians are changing. The work of veterinarians is no longer restricted to curative medicine in the interest of individual animals and their owners. A modern veterinarian must also have the competence to take collective and global perspectives into account and has responsibilities to care for animal welfare and public health as well (Meijboom 2018). According to Rollin, the most fundamental question of veterinary ethics is whether a veterinarian morally owes primary allegiance towards the owner or the animal (Rollin 2006). Nowadays, veterinarians in animal food production also have to consider the interests of the food companies, retail, consumers and society. Mostly, neither veterinary legislation nor professional codes offer veterinarians much support in case of conflicting values or interests. For instance, the Dutch Animal Law states that veterinarians have a duty of care towards animals (Ministry of Agriculture, Nature and Food Quality 2011). However, how they should act when this duty of care conflicts with other responsibilities, that society imposes on veterinarians, is not clear from the legal text. In their Code of Conduct, the Federation of Veterinarians of Europe (FVE) acknowledge that on occasions, obligations may conflict with each other and therefore the veterinarian may be presented with a dilemma. In such situations, FVE indicates that it is the individual veterinarian's responsibility to balance these obligations (Federation of Veterinarians in Europe 2009). In reality, many veterinarians are struggling with this plethora of responsibilities. In daily practice veterinarians often have to deal with situations where human and animal interests are in conflict and no easy solutions are available.

Within the profession this has opened the discussion on veterinary responsibilities and how to deal with expectations from society. In the Netherlands, for instance, an open letter of a group of veterinarians organised in "The Caring Vets" led to an intense internal debate about the role of the profession in the transition towards a more sustainable type of animal husbandry (Caring Vets 2017). The Caring Vets claim that a veterinarian's main interest should be animal welfare. Many Dutch farm animal veterinarians do not deny the importance of animal welfare, but consider themselves to be also responsible for food safety, public health and increasing the economic profit of farmers. The tendency towards a stronger emphasis on the veterinary responsibility for animal welfare is also reflected by a position paper of the British Veterinary Association (BVA), in which the authors argue that neither emotions nor economic factors may trump animal welfare considerations (British Veterinary Association 2016). For instance, when a dog owner has emotional problems to euthanize his/her companion who is suffering an incurable disease, this should not withhold a veterinarian to do what is best for the animal. If emotions of animal owners and societal expectations of the profession result in a conflict of 
professional responsibilities, this can be a source for moral dilemmas. The BVA argues that improving animal welfare should be the profession's primary aim and motivation. The profession's increased concern for animal welfare seems one of the answers to deal with the complex of societal expectations regarding veterinary responsibilities. However, if this would turn into a one-dimensional focus on either animal welfare or economics, it would do no justice to the broader spectrum of public expectations towards the veterinarian. Veterinarians are expected to promote public health and the health of the environment too. This is not only a public expectation, it is also acknowledged as a professional responsibility by the profession. It is broadly recognized that with their cross-species pathobiological expertise, veterinarians can make an essential contribution to public health.

However, to make all these veterinary responsibilities operational if concerns for health of humans, animals and nature are in conflict, is not easy. For example, in the case of antimicrobial resistance this becomes apparent when vets prescribe colistin to cure post-weaning diarrhoea (PWD) in piglets. PWD is an important economic problem in the swine industry, associated with a proliferation of enterotoxigenic E. coli bacteria in the pig intestine. Although treatment with colistin is effective, its use has also led to the development of (multi)resistant E. coli strains in swine. Moreover, in human medicine colistin is considered a 'last resort' therapy for certain bacterial infections. The discovery of new resistance genes, which can be easily transferred to other bacteria, has therefore raised concerns about the use in animal husbandry. However, alternative strategies to control PWD are complex, costly and depend on the competence, possibilities and willingness of farmers. For this reason, alternative strategies to control PWD are not as effective as antimicrobials (Rhouma et al. 2017). Despite the risks for public health, veterinarians therefore still treat PWD with antimicrobials like colistin to safeguard the health and welfare of piglets. Many veterinarians are aware of this dilemma but feel that, when they are not able to change the circumstances responsible for the disease, they have a strong duty to ensure the health of the piglets. Therefore, they often do not see other options on the short term than to treat the piglets with antimicrobials.

This example shows that veterinarians are constantly struggling to balance all these different professional responsibilities. Many veterinarians have great difficulty weighing all the interests in play. Without bad intent, this sometimes leads to unintended (but foreseeable) negative consequences for either public or animal health. Decisions become even more complicated when other interests join in as well. Veterinarians working in the context of the food industry, for instance, also have to deal with the economic interests of farmers and other parties in the food chain. At first glance, it seems that One Health only adds up to this complexity. The One Health framework requires veterinarians to cooperate with other health professionals to combat zoonotic diseases in order to protect public health. Within a narrow interpretation of the One Health concept this could imply that veterinarians should prevail human interests over animal health and welfare. However, we argue that these conflicts and difficulties are not the result of the One Health approach. It only makes the existing complexity explicit. In our view, the One Health concept can provide answers to mitigate these moral problems that veterinarians are facing.

\section{What One Health has to Offer}

It is clear that in cases as described above, a straight forward application of the One Health concept will not lead to an easy fix. On the contrary, current interpretations of One Health give 
veterinarians little moral guidance to deal with the responsibility conflicts they experience. It clearly specifies that human, animal and ecosystem health have to be addressed in an integrated way, but it does not yet prescribe how exactly the relation between human, animal and ecosystem health should be shaped. This step, however, is essential to guide veterinarians in real life cases, such as the example on post-weaning diarrhoea. The question than is: how can the One Health concept support veterinarians to strengthen their position?

To find some common ground on the normative aspects of One Health, we start on the level where there is consensus. That is with regard to the claim that it requires a closer cooperation between veterinary and human medicine. In the case of zoonotic diseases, this resulted in sharing and assessing disease signals. However, although the importance of these integrated human-veterinary risk analysis structures cannot be denied, this only covers part of the answer, because (a) the cooperation as such is not novel and (b) it represents a reactive strategy to address zoonotic health risks.

With regard to the first point, collaboration between veterinarians and human medicine is not as new as presented. In an historic analysis of zoonotic disease control in the Netherlands (1898-2001) Haalboom concludes that the interdisciplinary cooperation was not the biggest concern. She claims that the real problem of ineffective zoonotic disease control was an underlying conflict of interest between public health and economic interests of the food industry (Haalboom 2017). The serious consequences of these conflicts of interest became evident in the Q-fever epidemic that affected the Netherlands from 2007 to 2010. A difference of opinion between the Ministries of Health and Agriculture on the causality and the scientific evidence for interventions hindered an adequate approach. Finally, the continuous increase in human patients forced the government to cull 50.000 healthy and pregnant goats. Yet, there were indications that a vaccination strategy could have stopped the epidemic as well, if it was applied earlier (Van Dijk et al. 2010).

This leads to the second problem: in its current form the cooperation leads to a reactive strategy to public health risks. Some interpretations of the One Health concept, especially in zoonotic disease control policies seem to suggest that veterinarians should mainly identify and combat zoonotic disease threats for the sake of human health (National Institute for Public Health and the Environment 2019a). This view can be recognized in prominent One Health strategies to combat zoonotic diseases in livestock, like Avian Influenza, Q-fever or antimicrobial resistance. The focus is on public health and the approach mainly reactive and curative. Monitoring and controlling zoonotic diseases with the use of methods like screening, restrictions of animal movement, post-outbreak vaccination and culling is still standard in official Dutch policy documents (Ministry of Agriculture, Nature and Food Quality 2019). The economic considerations that underlie the non-vaccination policies and EU-regulations only further stress the central position that human interests have in the current situation.

We agree on the importance of One Health in stimulating cooperation between specialisations and contributing to openness and combining different perspectives. However, we argue that this is not enough. In our opinion, the debates on zoonotic disease control and the role of the veterinary profession would benefit from a broader, more holistic perspective on One Health. First, this entails the recognition of the independent value of animal health and environmental health, rather than considering animals and nature as mere sources of infectious diseases or other public health risks. In our view, a true One Health approach to zoonotic diseases should not only promote public health but should result in better health of animals and the environment as well. Second, it entails attention to underlying health risks rather than a focus on disease symptoms only. Such a frame offers opportunities for veterinarians to address 
the underlying reasons for public health threats coming from animal husbandry. This is a more effective approach to deal with public health issues than reactive strategies to signal and control outbreaks. To structurally improve human and animal health, it is therefore necessary to publically discuss the negative externalities of livestock farming. ${ }^{1}$

Based on their expertise, veterinarians can and should play an important role in this debate by explaining the impact of livestock farming on human and animal health, e.g., by stressing the animal and human health costs of certain types of types of animal production. Moreover, in the long run this strategy could help individual veterinarians to prevent certain value conflicts between animal health and public health as they encounter in practice. Rather than solving all problems, this implies that veterinarians should share their concerns with society via recommendations to public policy, formulating and communicating position papers and hands-on advice to animal owners. In this way the veterinary profession can contribute to the public debate on sustainable livestock production. The Dutch approach to tackle antimicrobial resistance is an example of how this could work.

\section{One Health in Practice: the Need for a System Approach}

In a small country like the Netherlands, the number of farm animals (125 million) exceeds the number of humans (17 million) by a sevenfold (Central Bureau of Statistics, PBL Netherlands Environmental Assessment Agency, and Wageningen University, and Research 2016). In this context, animals and humans have a direct and mutual impact on each other's health. If we focus on the effects of animals on human health, especially food producing animals are associated with several public health risks. Sometimes, this comes with far-reaching consequences, e.g., from 2007 to 2010 a Q-fever epidemic infected more than 4000 people and resulted in the death of 74 persons (National Institute for Public Health and the Environment $2019 b$ ). The fast increase of goat farms in the south eastern part of The Netherlands was one of the main causes of this severe outbreak of human Q fever (Roest et al. 2011).

The risk of zoonotic disease transmission from farm animals to humans is greatly influenced by the current system of intensive livestock farming (Kimman et al. 2013). Over the past decades, intensification of livestock farming in the Netherlands was predominantly driven by reducing costs. Because of the pressure of global markets on food prices, retail and food producers forced farmers to scale up and focus on maximizing production against the lowest possible costs. Within this system, veterinarians and farmers still attempt to keep animals healthy. However, due to these suboptimal economic circumstances addressing health problems with high use of antimicrobials seemed to be most effective. It simply was a cheaper option to (prophylactically) treat bacterial diseases with antimicrobials than to invest in biosecurity, feed or housing.

As a result, until 2007 the Netherlands led the European charts of antimicrobial use in farm animals (Grave et al. 2010). It is clear that the use of antimicrobials in animals causes antimicrobial resistance in pathogenic and commensal bacteria in animals. Although it is difficult to prove a direct link between the use of antimicrobials in farm animals and antimicrobial resistance in human patients (Tang et al. 2017), there is scientific and public

\footnotetext{
${ }^{1}$ Apart from the impact on public health, intensive livestock farming is also responsible for environmental problems like climate change, soil degradation and loss of biodiversity (Seinfeld et al. 2006). However, in this paper, we predominantly focus on issues concerning human and animal health.
} 
consensus on the importance of restrictive use of antimicrobials in animal husbandry due to its potential impact on public health. Especially the misuse of antimicrobials in healthy animals is considered a threat to human health because of the possible loss of effective antimicrobials for human medicine (World Health Organization 2017). Because of this risk, the Dutch government has issued strict policies for antimicrobial use in animals. This resulted in the so-called 'Dutch Model' which appeared to be very effective and led to a significant reduction of antimicrobial use. Internationally this policy has even been presented as an example for antimicrobial reduction policies in animal husbandry (Sheldon 2016) The success of the strategy can be partly attributed to a stronger position of veterinarians on farms (mandatory one-on-one contract, herd health plan and regular farm visits), registration and benchmarking of antimicrobial use, vaccination strategies and better biosecurity (Food and Veterinary Office 2017).

Although initially farmers and veterinarians were worried about the negative effects of antimicrobial reduction policies, it seems that to date, there is little evidence that animal health is seriously affected (Council on Animal Affairs 2016). Apparently, veterinarians and farmers were able to safeguard animal health in other ways, such as vaccination and improving biosecurity. This seems to fit perfectly in a One Health perspective, because eventually the health of humans, animals and the environment has benefited from the reduction of antimicrobial use. However, in spite of the success, new questions arise. Dutch politicians argued that to protect public health, antimicrobial consumption in livestock should be as low as possible. As a result, the current question in the Netherlands is whether it is possible to reduce antimicrobial use any further than the $64,4 \%$ decrease that is achieved so far (year of reference 2009). The Dutch government and the Veterinary Medicines Authority both indicate that additional reduction is indeed possible, certainly on farms that currently are registered as structural high users (Ministry of Agriculture, Nature and Food Quality and Ministry of Health, Welfare and Sport 2016; Netherlands Veterinary Medicine Institute 2018) This will probably be true, although it is not realistic to expect that antimicrobial use in animals could be banned totally. As long as society considers livestock farming socially and ethically acceptable, a certain amount of antimicrobials will always be necessary to treat bacterial infections in farm animals.

Veterinarians are regarded as a key factor in current and future antimicrobial reduction policies in the Netherlands. Still, even on farms with a structural high use, veterinarians will consider it their professional responsibility to treat sick animals with antimicrobials. So as long as farmers are not willing or able to implement the veterinarian's advice about alternative measures to prevent bacterial infections, it will be difficult to make further progress. We therefore argue that to achieve a level of antimicrobial use in livestock farming that can be considered as low as reasonably possible, requires an approach on a system level. In our view, the main underlying problem in livestock farming is a one-sided focus on maximizing production at minimum costs to produce cheap animal protein. This leads to animal health (and -welfare) problems and risks. Moreover, it substantially reduces the farmers' ability to change and innovate. As a consequence, veterinarians' recommendations to make more fundamental changes in management or housing, in order to reduce disease problems, are not followed. Quite often this is not a problem of unwillingness of farmers, but the result of financial inability.

Since veterinarians still consider it their moral obligation to treat sick animals, this situation forces them to prescribe antimicrobials, which brings along human health risks. To stop this race to the bottom, a holistic view on the One Health perspective can teach us two lessons. 
First, it is necessary to address the fundamental problems of intensive livestock farming, rather than attempting to maintain animal health with the use of antimicrobials under difficult circumstances. Second, we should get rid of the dichotomy from which it seems one has to choose between either human health or animal health. If we address the cost-only perspective of animal husbandry and start from an 'encapsulated health' perspective, i.e., keeping our animals healthy and caring for their welfare, this will automatically contribute to the reduction of zoonotic disease risks and thereby promote human health. In this process, veterinarians should play an important role. They already have their Aesculapian authority (cf. Rollin 2002) that enables them to inform the public about the underlying causes of problems, such as antimicrobial resistance, in order to start a change.

\section{Health: a Matter of Resilience}

A holistic conception of One Health could provide veterinarians further tools to address the negative aspects of intensive livestock farming and to stimulate more sustainable and socially acceptable production systems. A prerequisite of such a system would be: not to harm the health of humans, animals and the environment. Therefore, the starting point for any livestock production system should be that the health of animals is central. However, One Health does not come with a standard definition of health. Nonetheless, conceptual clarity on this level is important to respond to problems such as antimicrobial resistance in a way that takes animals, humans and nature into account.

There are many definitions of human, animal and environmental health. In veterinary medicine health is sometimes defined in terms of production or reproduction (Gunnarsson 2006). From this perspective, one could maintain that a focus on production automatically implies that animals have to be healthy if a farmer wants to keep his or her farm profitable. However, it is clear that pushing animals towards high productivity increases the risk of certain diseases (Rauw et al. 1998). Within the context of zoonotic diseases and antimicrobial resistance it seems appropriate to understand health as the absence of disease (cf. Boorse 1977). This definition is understandable for veterinary practioners and gives them a reason to promote disease prevention. However, applying this definition to characterize the health of ecosystems, is difficult because bacteria and viruses, that can cause (zoonotic) diseases, are an essential part of balanced ecosystems.

Therefore, within the One Health framework some have proposed to understand health as resilience (Döring et al. 2015; van Herten et al. 2019). Resilience can be interpreted as the persistence of systems and their ability to absorb change and disturbance and still maintain the same relationships between populations or state variables (Holling 1973). From this perspective one can, for instance, learn that in many situations in intensive livestock farming external forces like insufficient housing, food and management have outbalanced the internal capacities of animals to react and stay healthy. Ge et al. describe that current animal production systems are developed to maximize production and efficacy under standard conditions, which makes them vulnerable to (unanticipated) external influences. Inadequate functioning or overstimulation over longer periods of time can lead to disease (Ge et al. 2016). These production related diseases can therefore be considered as a sign that current intensive animal production systems are not resilient.

The concept of resilience can be applied to all components of One Health: humans, animals and ecosystems. For this reason, Döring et al. present resilience as a universal criterion for 
health (Döring et al. 2015). They emphasize the importance of an animal's ability to react, balance and restore itself to a certain degree, given that the surroundings allow this, to reach a status that can be described as healthy. This view is compatible with modern definitions of animal welfare, of which health is an inseparable part. Ohl and Van der Staay, for instance, argue that an individual animal is in a positive welfare state when it has the freedom to display normal behavioural patterns, allowing it to adapt to the demands of the prevailing environmental circumstances and enable it to reach a state that the animal perceives as positive (Ohl and van der Staay 2012). Nowadays, in human medicine comparable balance theories of health are prominent as well. In this perspective, Huber advocates to define health as the ability to adapt and self-manage (Huber 2011). Finally, others applied the concept of resilience to characterize the health of ecosystems. Constanza considers an ecological system healthy if it is stable and sustainable, i.e. if it is active and maintains its organization and autonomy over time, and is resilient to stress (Costanza 2012). Since it is universally applicable to humans, animals and the environment, we believe the idea of health as resilience contributes to operationalizing a One Health strategy to tackle antimicrobial resistance. This is because in the context of animal husbandry it provides grounds to transform animal production systems in a way that resilience of animals is promoted. Consequently, human and environmental health will benefit from this as well.

\section{Veterinary Organizations and One Health}

With its specific expertise, the veterinary profession is qualified to guide this transition towards a sustainable animal husbandry in which antimicrobial use can be minimized further. For individual veterinarians starting this process can be problematic. This is not rooted in moral indifference. For most veterinarians the main concern is the health and welfare of the animals under their care. However, the influence of farm animal veterinarians is sometimes limited because of their role as service-provider: they provide veterinary care on request of farmers. Farmers primarily expect veterinarians to do what they are consulted for. Therefore, interventions are sometimes only directed at solving disease problems in the short-term. Of course, veterinarians will advise farmers how to prevent diseases and have healthier animals in the long-term as well. However, this can be difficult because in this context veterinarians are dependent on the will and the (financial) possibilities of farmers to change circumstances for the better of their animals. Moreover, public health problems like antimicrobial resistance are of global concern and go beyond the sphere of influence of individual veterinarians. On such a scale their impact is limited. Although the commitment of individual veterinarians is essential in national reduction policies, to effectively address the issue of antimicrobial resistance on a global level a more collective approach in necessary.

Therefore, we propose to start this change at the level of professional organisations of veterinarians. They have a different position. They can translate veterinary concerns into position papers that transcend the problems on individual farms. Veterinary organisations should publicly address structural underlying causes in the food production chain that precede diseases in animals, like the transport of veal calves or growth rate in broilers. They should call on all responsible parties in the food production chain (farmers organisations, food producers, banks and retail) as well as the government and consumers to take action. By doing so, veterinary associations will support individual veterinarians in their daily work to improve animal health and welfare on the farm level. Veterinarians truly contribute to the idea of One 
Health if they collectively promote livestock systems that are not primarily focussed on production results and cost-reduction but on animal health and welfare.

However, not many veterinary organizations publicly address the problems of intensive animal husbandry in the name of One Health. Just like many individual farm animal veterinarians, national veterinary professional organizations seem reticent to take an explicit stand for animal health and welfare. In 2017, the World Veterinary Association (WVA) adopted the so-called declaration of Incheon that described the role of the veterinary profession in One Health and Eco Health initiatives. The WVA emphasizes the importance of policy engagement and professional leadership to address One Health issues. Moreover, the veterinary profession should "assertively advocate for and protect the welfare of all animals living in all environments. Veterinarians are educated to skilfully evaluate animal health and welfare, which are dependent upon proper housing, management, nutrition, disease prevention and treatment, responsible care and humane handling" (World Veterinary Association 2017). In relation to antimicrobial resistance, the FVE endorse the idea of 'prevention is better than cure' by stating that "animals that are well cared for and appropriately housed, will experience better welfare, be less prone to infections and will need fewer antimicrobials" (Federation of Veterinarians in Europe 2016). FVE acknowledges the need to improve biosecurity and hygiene in animal husbandry to reduce bacterial infections and corresponding treatments with antimicrobials. Moreover, FVE recommends to promote positive welfare steps to reduce stress and therefore susceptibility to infections. Besides productivity, farm animal breeders should incorporate breeding goals on health and longevity, including disease resistance, to decrease the need for antimicrobial treatments (Federation of Veterinarians in Europe 2016).

Despite these clear and urgent calls from international veterinary organizations, it seems that on a national level not much progress has been made. A small desktop research ${ }^{2}$ on websites of national veterinary organizations did not reveal publications that addressed the negative externalities of livestock production systems and the need to change for the benefit of human, animal and environmental health. Up till now, we don't know of a successful campaign from the veterinary profession that advocates radical change of animal production systems. Currently in the Netherlands, a relatively small group of veterinarians organised in the 'Caring Vets' has taken a stand on several animal welfare issues like calf-cow seperation, tail docking in pigs and mega-farms (Nalon 2017). However, they focus primarily on animal welfare and leave public or environmental health out of the discussion. In Germany, a comparable veterinary organization, Tierärztliche Vereinigung für Tierschutz, mainly criticizes livestock farming because of the related animal welfare issues, like castration of piglets, animal transport and dehorning of cattle. In a recent position paper on disease surveillance the BVA acknowledges the importance of animal health and welfare for public health and trade in animal products. In line with OIE, they advocate the important role of veterinarians in monitoring diseases by acting as sentinel for wider human and animal health, underpinned by a common 'One Health' rationale to minimise harm (British Veterinary Association 2018). Although improvement of veterinary surveillance will certainly contribute to animal as well as public health, unfortunately in this paper the BVA did not point out the underlying reasons for many public health threats coming from intensive livestock farming. In our opinion, a missed opportunity to fundamentally apply One Health thinking.

\footnotetext{
${ }^{2}$ Online search strategy looking at media publications and position papers of national veterinary organizations in Europe, Canada and the United States.
} 
Of course occasionally individual veterinarians have spoken out for preventive population health to reduce the need for curative interference, like the prescription of antimicrobials (Davies 2017). However, on the level of national veterinary organizations there seems to be a relative silence about the need to change livestock production in the context of One Health. One of the reasons for this could be that just like veterinarians, who are financially dependent on their clients, veterinary organizations are equally dependent on their members. Without a considerable representation of the veterinary profession, veterinary organizations are often not successful in influencing policy making and contributing to public debate. Furthermore, because of differentiation and specialisation in the profession, veterinary organizations have a very diverse membership. For instance, companion animal veterinarians often have totally different views about the ethical acceptability of livestock production systems than their colleagues in farm animal medicine. This moral plurality sometimes makes it difficult to publish very pronounced statements.

\section{Professional Integrity and Leadership}

In the case of antimicrobial-resistance the relationship between veterinarian and farmer is of great influence on the success of reduction policies. An important factor here is the level of independency and authority of veterinarians to resist the demand of certain farmers to prescribe antimicrobials when there is no strict veterinary need (Speksnijder et al. 2015). In this context, the notion of professional integrity plays an important role. When veterinarians are confronted with a conflict of interest between the profession's core values (animal health, animal welfare and public health), they have to be able to balance between accommodation of their client's wishes and professional integrity. Professional integrity, in terms of a commitment to the profession's aims and principles, can help veterinarians to motivate their actions and to show why decisions are not just arbitrary or opportunistic (Meijboom 2018). Professional standards or position papers can support individual veterinarians with these, sometimes, difficult decisions on the farm.

In the Netherlands, veterinary organizations often cooperate with farmer organizations and representatives of the pharmaceutical industry to realize their goals. At the same time, they consult with the government and animal welfare organizations. The influence of veterinary organizations and whether they are successful in promoting the interests of their members depends greatly on the relationship with these stakeholders. However, in our opinion just like individual veterinarians, veterinary organizations should be aware of maintaining their integrity. A certain independence of veterinary organizations is a prerequisite to preserve the trust of the general public. For this reason, the profession needs a well-functioning self-regulatory system (May 2018). To promote the longterm interests of the veterinary profession, veterinary organizations should overcome short term (economic) interests of some individual members or certain stakeholders. Instead, veterinary organizations have to develop and show professional leadership to meet societal expectations and to maintain professional autonomy. Rather than addressing symptoms and solving moral problems that arise from intensive livestock farming, this idea of leadership entails that the veterinary profession makes these moral issues including the underlying system problems visible to society. This step is not a kind of buck passing, but to show that dealing with current challenges cannot be a task of farmers and veterinarians only. After all, existing livestock production systems are shaped by societal developments and demands. Therefore the responsibility for innovation and transformation of livestock farming into a practice that does justice to human, animal and ecosystem health is not restricted to one group in society, but requires an integrated approach. Still, in this debate the 
veterinary profession has an independent position to promote animal health, which arises from their professional veterinary responsibilities. By doing so they encapsulate human and environmental health as well.

\section{Conclusion}

To tackle zoonotic disease threats from intensive livestock farming, like antimicrobial resistance, One Health strategies are indispensable. However, the One Health concept does not yet prescribe exactly how the relation between human, animal and ecosystem health should then be shaped to fundamentally address zoonotic diseases. We argue that these health issues require a system level approach. Furthermore, it is essential to use an integrated view on health, rather than focussing solely on human health. Such a perspective forces us to address the underlying health risks of intensive livestock production instead of treating only the symptoms. Veterinarians can play an important role in this context.

In our opinion, to optimally promote One Health the primary interest of veterinarians should be: to promote animal health. We call this the 'encapsulated health' argument. Instead of the current curative and control focussed perspective in zoonotic disease control, veterinarians should advocate that healthy animals are an essential precondition of any type of livestock production system. If these systems are constructed to secure animal health this will eventually benefit human and environmental health. Interpreted as such, One Health offers a way out of the dichotomy between public and animal health that is at the basis of many moral dilemmas in zoonotic disease control.

This transition starts with veterinarians who give animal health and -welfare priority over (economic) interests of farmers and the food production chain when human health is at stake. On an individual level this is a difficult task for veterinarians since they are financially dependent on farmers. Moreover, to initiate a change on a system level, individual veterinarians often fall short in power and capacities. This would overburden individual professionals. Therefore, we proposes that professional organisations of veterinarians should play an important role here. By joining forces, veterinarians within these organisations have more power, scope and options. As a result, they can publicly address health issues, call for the necessary structural changes and support individual veterinarians and farmers in making a step from a curative control-based approach to a strategy that focuses on prevention. In this way, our idea of 'encapsulated health' functions on an individual as well as on an organisational level. In the long run, we expect that such a preventive approach can mitigate possible conflicts between animal health and public health that veterinarians are confronted with.

Open Access This article is distributed under the terms of the Creative Commons Attribution 4.0 International License (http://creativecommons.org/licenses/by/4.0/), which permits unrestricted use, distribution, and reproduction in any medium, provided you give appropriate credit to the original author(s) and the source, provide a link to the Creative Commons license, and indicate if changes were made.

\section{References}

American Veterinary Medical Association (AVMA). 2008. One health: A new professional imperative, one health initiative task force final report. Washington, DC. https://www.avma. org/KB/Resources/Reference/Pages/One-Health94.aspx. Accessed 8 Feb 2019. 
Boorse, C. 1977. Health as a theoretical concept. Philosophy of Science 44 (4): 542-573. https://doi.org/10.1086 1288768 .

British Veterinary Association (BVA). 2016. Animal welfare policy position. London. https://www.bva.co. uk/News-campaigns-and-policy/Policy/Ethics-and-welfare/Animal-welfare/. Accessed 28 Jan 2019.

British Veterinary Association (BVA). 2018. BVA position on veterinary scanning surveillance (animal health and disease monitoring). London. https:/www.bva.co.uk/uploadedFiles/Content/News_campaigns_and policy/Policy/Animal_disease_surveillance/BVA\%20position $\% 20$ on $\% 20$ veterinary $\overline{\%} 20$ scanning $\% 20$ surveillance.pdf. Accessed 28 Jan 2019.

Caring Vets. 2017. "Come in opposition veterinarians. This is not animal welfare." Open letter in NRC newspaper. https://www.nrc.nl/nieuws/2017/06/26/kom-in-verzet-dierenarts-dit-is-geen-dierenwelzijn11289973-a1564575. Accessed 28 Jan 2019.

Central Bureau of Statistics, PBL Netherlands Environmental Assessment Agency, and Wageningen University \& Research. 2016. Development of Livestock on Farms in the Netherlands, 1980-2015. 2016. Wageningen https:/www.clo.nl/indicatoren/n12124-ontwikkeling-veestapel-op-landbouwbedrijven-.Costanza. Accessed 28 Jan 2019.

Costanza, R. 2012. Ecosystem health and ecological engineering. Ecological Engineering 45 (August): 24-29. https://doi.org/10.1016/j.ecoleng.2012.03.023.

Council on Animal Affairs. 2016. Antibiotic policy in animal husbandry. The Hague. https://english.rda. nl/publications/publications/2016/03/01/antibiotic-policy-in-animal-husbandry-effects-and-perspectives. Accessed 24 Aug 2018.

Davies, P. 2017. Balancing responsibilities when prescribing antimicrobials for farm animals. Veterinary Record 180 (15): 374-375. https://doi.org/10.1136/vr.j1708.

Degeling, C., Z. Lederman, and M. Rock. 2016. Culling and the common good: Re-evaluating harms and benefits under the one health paradigm. Public Health Ethics 9 (3): 244-254. https://doi.org/10.1093 /phe/phw019.

Döring, T.F., A. Vieweger, M. Pautasso, M. Vaarst, M.R. Finckh, and M.S. Wolfe. 2015. Resilience as a universal criterion of health. Journal of the Science of Food and Agriculture 95 (3): 455-465. https://doi.org/10.1002 jjsfa.6539.

Federation of Veterinarians in Europe (FVE). 2009. European veterinary code of conduct. https://www.fve. org/cms/wp-content/uploads/bro_fve_2009_final-1.pdf. Accessed 8 Feb 2019.

Federation of Veterinarians in Europe (FVE). 2016. Relationship between animal welfare and the use of antibiotics in food animals. http://www.fve.org/uploads/publications/docs/063_fve_aww_position_on_ resistance_and_animal_welfare_final2.pdf. Accessed 8 Feb 2019.

Food and Veterinary Office. 2017. Final Report Prudent Use of Antimicrobials in the Netherlands. DG(SANTE) 2016-8889-MR. http://ec.europa.eu/food/audits-analysis/audit_reports/details.cfm?rep_id=3753. Accessed 28 Jan 2019.

Ge, L., N.P.R. Anten, I.D.E. van Dixhoorn, P.H. Feindt, K. Kramer, R. Leemans, M.P.M. Meuwissen, H. Spoolder, and W. Sukkel. 2016. Why we need resilience thinking to meet societal challenges in bio-based production systems. Current Opinion in Environmental Sustainability 23 (December): 17-27. https://oi. org/10.1016/j.cosust.2016.11.009.

Grave, K., J. Torren-Edo, and D. Mackay. 2010. Comparison of the sales of veterinary antibacterial agents between 10 European countries. Journal of Antimicrobial Chemotherapy 65 (9): 2037-2040. https://doi. org/10.1093/jac/dkq247.

Gunnarsson, S. 2006. The conceptualisation of health and disease in veterinary medicine. Acta Veterinaria Scandinavica 48 (1). https://doi.org/10.1186/1751-0147-48-20.

Haalboom, A.F. 2017. Negotiating Zoonoses: Dealings with infectious diseases shared by humans and livestock in the Netherlands (1898-2001). Utrecht University. https://dspace.library.uu.nl/handle/1874/354208. Accessed 8 Feb 2019.

Holling, C.S. 1973. Resilience and stability of ecological systems. Annual Review of Ecology and Systematics 4 (1): 1-23. https://doi.org/10.1146/annurev.es.04.110173.000245.

Huber, M. 2011. Health: How should we define it? British Medical Journal 343 (July): 4.

Kimman, T., M. Hoek, and M.C.M. de Jong. 2013. Assessing and controlling health risks from animal husbandry. NJAS - Wageningen Journal of Life Sciences 66 (November): 7-14. https://doi.org/10.1016/j. njas.2013.05.003.

Lerner, H., and C. Berg. 2015. The concept of health in one health and some practical implications for research and education: What is one health? Infection Ecology \& Epidemiology 5 (1): 25300. https://doi.org/10.3402 /iee.v5.25300.

May, S.A. 2018. Protecting society: The value of the professional regulatory model. In Professionals in food chains, 25-29. Vienna: Wageningen Academic Publishers. https://doi.org/10.3920/978-908686-869-8_1. 
Meijboom, F.L.B. 2018. More than just a vet? Professional integrity as an answer to the ethical challenges facing veterinarians in animal food production. Food Ethics 1 (3): 209-220. https://doi.org/10.1007/s41055-0170019-z.

Meijboom, F.L.B., and J. Nieuwland. 2018. Manifold health: The need to specify one health and the importance of cooperation in (bio)ethics. In Professionals in food chains, 266-271. Vienna: Wageningen Academic Publishers. https://doi.org/10.3920/978-90-8686-869-8 41.

Ministry of Agriculture, Nature and Food Quality. 2011. “Animal Law.” Dutch government. 2011. https://wetten. overheid.nl/BWBR0030250/2019-01-01\#Hoofdstuk4_Artikel4.2. Accessed 28 Jan 2019.

Ministry of Agriculture, Nature and Food Quality. 2019. Policy documents zoonotic and animal diseases. Official website ministry of Agriculture, Nature and Food Quality. 2019. https://www.rijksoverheid. nl/onderwerpen/dierziekten/bestrijding-dierziekten/beleidsdraaiboeken-dierziekten. Accessed 28 Jan 2019.

Ministry of Agriculture, Nature and Food Quality, and Ministry of Health, Welfare and Sport. 2016. Letter to the parliament on forthcoming policy on antimicobial use in livestock. July 8, 2016. https://www.rijksoverheid. nl/documenten/kamerstukken/2016/07/08/kamerbrief-over-vervolgbeleid-antibiotica-in-de-veehouderij. Accessed 28 Jan 2019.

Nalon, E. 2017. Veterinarians speak out against systematic abuse of farm animals. June 27, 2017. https://www. linkedin.com/pulse/veterinarians-speak-up-against-systematic-abuse-farm-animals-nalon. Accessed 11 Feb 2019.

National Institute for Public Health and the Environment. 2019a. One Health: about One Health. 2019. https://onehealth.nl/over-one-health. Accessed 28 Jan 2019.

National Institute for Public Health and the Environment. 2019b. Q Fever. 2019. https://www.rivm.nl/q-koorts. Accessed 28 Jan 2019.

Netherlands Veterinary Medicine Institute. 2018. Usage of antibiotics in agricultural livestock in the Netherlands in 2017 trends and benchmarking of livestock farms and veterinarians. http://www. autoriteitdiergeneesmiddelen.nl/Userfiles/AB\%20gebruik\%202017/engels-def-rapportage-2017.pdf. Accessed 8 Feb 2019.

Ohl, F., and F.J. van der Staay. 2012. Animal welfare: At the Interface between science and society. The Veterinary Journal 192 (1): 13-19. https://doi.org/10.1016/j.tvj1.2011.05.019.

Pinillos, R. García, M.C. Appleby, X. Manteca, F. Scott-Park, C. Smith, and A. Velarde. 2016. One welfare - A platform for improving human and animal welfare. Veterinary Record 179 (16): 412-413. https://oi. org/10.1136/vr.i5470.

Rauw, W.M., E. Kanis, E.N. Noordhuizen-Stassen, and F.J. Grommers. 1998. Undesirable side effects of selection for high production efficiency in farm animals: A review. Livestock Production Science 56 (1): 15-33. https://doi.org/10.1016/S0301-6226(98)00147-X.

Rhouma, M., J.M. Fairbrother, F. Beaudry, and A. Letellier. 2017. Post weaning diarrhea in pigs: Risk factors and non-Colistin-based control strategies. Acta Veterinaria Scandinavica 59 (1) https://doi.org/10.1186/s13028017-0299-7.

Roest, H.I.J., J.J.H.C. Tilburg, W. Van Der Hoek, P. Vellema, F.G. Van Zijderveld, C.H.W. Klaassen, and D. Raoult. 2011. The Q fever epidemic in the Netherlands: History, onset, response and reflection. Epidemiology and Infection 139 (01): 1-12. https://doi.org/10.1017/S0950268810002268.

Rollin, B.E. 2002. The use and abuse of Aesculapian authority in veterinary medicine. JAVMA 22 (8): 1144 1149 .

Rollin, B.E. 2006. An introduction to veterinary medical ethics: Theory and cases. 2nd ed. Ames: Iowa State University Press.

Seinfeld, H., Gerber, P., Wassenaar, T., Gastel, V., Rosales, M. and De Haan C. 2006. Livestock's long shadow. Food and Agricultural Organization of the United Nations. http://www.fao.org/docrep/010/a0701e/a0701 e00.HTM. Accessed 26 Nov 2018.

Sheldon, T. 2016. Saving antibiotics for when they are really needed: The Dutch example. BMJ, August, i4192. https://doi.org/10.1136/bmj.i4192.

Speksnijder, D.C., D.A.C. Jaarsma, T.J.M. Verheij, and J.A. Wagenaar. 2015. Attitudes and perceptions of Dutch veterinarians on their role in the reduction of antimicrobial use in farm animals. Preventive Veterinary Medicine 121 (3-4): 365-373. https://doi.org/10.1016/j.prevetmed.2015.08.014.

Stephen, C., and W. Karesh. 2014. Introduction: Is one health delivering results? Revue Scientifique Et Technique (International Office of Epizootics) 33 (2): 375-379.

Tang, K.L., N.P. Caffrey, D.B. Nóbrega, S.C. Cork, P.E. Ronksley, H.W. Barkema, A.J. Polachek, et al. 2017. Restricting the use of antibiotics in food-producing animals and its associations with antibiotic resistance in food-producing animals and human beings: A systematic review and meta-analysis. The Lancet Planetary Health 1 (8): e316-e327. https://doi.org/10.1016/S2542-5196(17)30141-9.

Van Dijk et al. 2010. Q-fever policy in the Netherlands 2005-2010. The Hague. http://library.wur. nl/WebQuery/edepot/156237. Accessed 19 Sep 2018. 
van Herten, J., and F.L.B. Meijboom. 2018. Veterinary responsibilities within the one health framework. In Professionals in food chains, 281-286. Vienna: Wageningen Academic Publishers. https://doi.org/10.3920 /978-90-8686-869-8 43.

van Herten, J., B. Bovenkerk, and M. Verweij. 2019. One health as a moral dilemma: Towards a socially responsible zoonotic disease control. Zoonoses and Public Health 66 (1): 26-34. https://doi.org/10.1111 /zph.12536.

World Health Organization (WHO). 2017. WHO guidelines on use of medically important antimicrobials in food-producing animals. Geneva, Switzerland. https://apps.who.int/iris/bitstream/handle/10665/258970 /9789241550130-eng.pdf;jsessionid=BB593A9387A91DA1A7326C5DCD7D2D4A? sequence=1. Accessed 28 Jan 2019.

World Veterinary Association (WVA). 2017. WVA declaration of Incheon. South Korea. http://www.worldvet. org/uploads/news/docs/wva_declaration_of_incheon_final.pdf. Accessed 29 Sep 2018.

Wright, N., F.L.B. Meijboom, and P. Sandøe. 2010. Thoughts on the ethics of preventing and controlling epizootic diseases. The Veterinary Journal 186: 127-128.

Publisher's Note Springer Nature remains neutral with regard to jurisdictional claims in published maps and institutional affiliations. 